\title{
Knowledge, Attitude and Practice Regarding COVID-19 and its Impact on Dentistry: A Cross-sectional Survey among Nepalese Dentists Khanal $N,{ }^{1}$ Singh $\mathrm{AK}^{2}$
}

${ }^{1}$ Department of Dentistry and Oral Health,

Bharatpur Samudayik Hospital,

Bharatpur, Nepal.

${ }^{2}$ Department of Oral and Maxillofacial Surgery,

College Of Medical Sciences-Teaching Hospital,

Bharatpur, Nepal.

\section{Corresponding Author}

Nikita Khanal

Department of Dentistry and Oral Health,

Bharatpur Samudayik Hospital,

Bharatpur, Nepal.

E-mail: drnikitakhanal@gmail.com

\section{Citation}

Khanal N, Singh AK. Knowledge, Attitude and Practice Regarding COVID-19 and Its Impact on Dentistry. A Cross-sectional Survey among Nepalese Dentists. Kathmandu Univ Med J. 2020;COVID-19 Special Issue 70(2):3-9.

\begin{abstract}
Background

Coronavirus Disease, 2019 (COVID-19) is a highly infectious respiratory disease with high transmissibility. Dentists are at inherent risk because of aerosol generating procedures exposing dentists to the respiratory and oral secretions of the patients.
\end{abstract}

\section{Objective}

To assess the knowledge, awareness, and practice (KAP) of the Dentists to combat the pandemic which could help shape future guidelines and policies to be implemented in dental settings.

\section{Method}

This cross-sectional descriptive study included series of multiple-choice questions distributed online, assessing dentists' KAP towards COVID-19, its impact on dentistry and their psychological well-being. Statistical analysis was performed using SPSS (Statistical Package for Social Sciences) version 20 for mac Operating System (OS). Descriptive statistics was performed, and frequencies of responses were reported in proportion. Non-parametric tests of independence and Chi-square test were performed to see the association between the categorical variables.

\section{Result}

Around $84 \%$ of the respondents accurately answered mode of transmission, $68 \%$ inquired about the travel history while only $49 \%$ measured the body temperature. Also, only $42 \%$ were receiving salary. A statistically significant difference concerning impact and practice during the COVID-19 was observed between general practitioner and specialist working at different work places.

\section{Conclusion}

Majority of Dentists have good knowledge and awareness but there were certain pitfalls in attitude and practice level calling out for more efficient training programs, precise guidelines, and treatment protocols to put into practice. Also, the mental distress and the financial impact subjected upon dentist require to be further explored determining the association between their mental health during and post COVID-19 outbreak.

\section{KEY WORDS}

Aawareness, Behavior, COVID 19, Dental care professionals, Knowledge 


\section{INTRODUCTION}

COVID-19, caused by severe acute respiratory syndrome corona virus 2 (SARS-CoV-2) presents as fever, dry cough, myalgia, and fatigue but might also complicate to acute respiratory distress syndrome with bleeding and coagulation dysfunction. ${ }^{1}$ Cross-transmission occurs via airborne droplets, touch of an infected person (shaking hands) or surface contact from a contaminated surface. ${ }^{2}$ Following the lockdown enforced on March 24 amid concerns of COVID-19 outbreak in Nepal, most of the dental practices are shut, however, dental emergencies could present.

It has been argued that under conditions where patient is symptom-free with no reasonable suspicion of having acquired the infection, dental care can still be given. ${ }^{3}$ Nonetheless, super-spreaders concerning those people who appear symptoms-free but could transmit it to others; are shown to have association in the spread of SARS (Severe Acute Respiratory Syndrome) outbreak around 20 years ago where $75 \%$ of infections occurred by a small number of 'super-spreaders'. ${ }^{4}$ Therefore, dentist could either unknowingly get infected and further spread the disease or by following definitive guidelines prevent the possible cross-transmission, saving the public from the devastating consequences.

There is also an imminent anxiety regarding lack of access to personal protective equipment (PPE) lack of proper standard protocol on management and possibility of financial crisis in the future. The objective of this study is to explore KAP of Nepalese dentists regarding COVID-19 and its impact in their practice, to help shape future guidelines to be implemented in dental settings to guarantee awareness regarding this global emergency and deliver safe and quality patient care.

\section{METHODS}

The cross-sectional descriptive study was conducted solely online with series of multiple choice questionnaires collecting responses till the determined sample size was reached. The ethical approval for the study was obtained from Nepal Health Research Council. Electronic informed consent was provided on the initial page of the survey. The positive response was considered as implied consent. The NMC registered Dentists who responded to all the questions of the survey were included while incomplete responses were excluded from the survey. The population size taken in this survey was NMC registered dentists who are around 1500 in Nepal. We considered, a 95\% confidence level. Confidence interval or margin of error, that tells how much we can expect our survey results to reflect the views of the overall population was kept at 10 , as smaller the margin of error, the closer we are to having the exact answer at a given confidence level. The calculated minimum sample size was 100 .
An online structured survey composed of 26 questions created using the free-access Google Forms application. Pretesting of the survey instrument was done and refinements were made as required to facilitate better comprehension and to organize the questions before the final survey instrument was formed. The questionnaire was pretested among ten dental surgeons in Bharatpur. Inter responder reliability was tested among five responders and was found to have high reliability. It was sent to dental practitioners with the link to the online survey sent through an anonymous mailing and social media messaging list to currently practicing dentists across the country regardless of their place of work either in private clinics, hospitals, or health centers. Confidentiality was maintained throughout the study by making participants' information anonymous and not asking to enter their personal details at any point. Eligible dentists' participation in this survey was completely voluntary. Filled proforma was collected via e-survey and after completion of the assigned sample size of participants; it was recorded in spreadsheet software as a master chart for statistical analysis. Statistical analysis was performed by the primary and secondary authors themselves using SPSS version 20 for mac OS. Descriptive statistics was performed, and frequencies of responses were reported in proportion. Nonparametric tests of independence and Chi-square test was performed to see the association between categorical variables.

\section{RESULTS}

A total of 106 dentists participated in this study with total of $62(58.5 \%)$ female and male $44(41.5 \%)$. The majority $75(70.8 \%)$ of the participants were of the age group 20-29 years followed by $30(28.3 \%)$ participants of $30-39$ years age group. Around 53(50\%) of the participants had less than 2 years of working experience subsequently $32(30.2 \%)$ had 3-5 years of practice followed by $15(14.2 \%)$ and $6(5.7 \%)$ participants having $5-10$ years and $>10$ years of working experience respectively. The responder's designated workplace and the provinces they work in are shown in figure 1. Almost 74(69.8) of the participants were General Practitioner (GP) while only 32(30.2) were Specialist (SP).

About $45 \%$ of the participants showed knowledge of 2019-nCoV as the virus causing COVID-19 which was later termed SARS-CoV-2. All the participants (100\%) answered Wuhan as the city reporting the first case. Around $84 \%$ accurately answered mode of transmission being the respiratory droplets and $93 \%$ of the respondents correctly identified the COVID-19 exposure situation which required medical attention. Also, $82 \%$ had accurate awareness of the hand hygiene method preferred for visibly soiled hands. Nevertheless, it was alarming that only $51 \%$ correctly defined "close contact".

Following the lockdown, which was enforced since March, $66(62 \%)$ had closed their practice but seeing emergency 

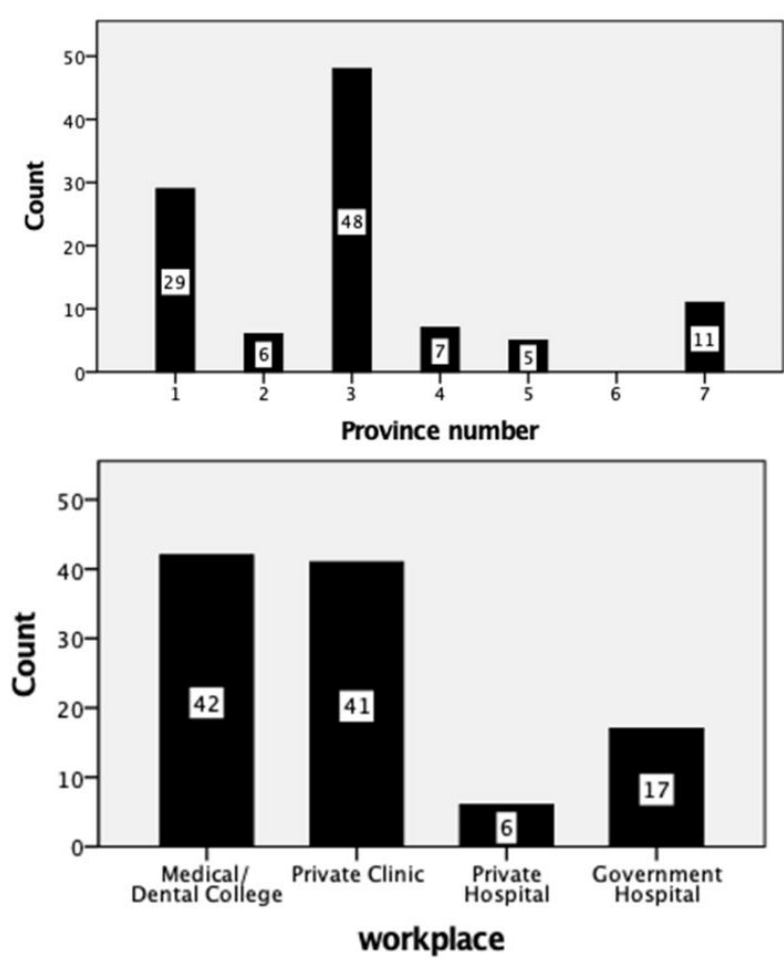

Figure 1. Participant's from different provinces and their designated workplace.

cases only. Only $11 \%$ specified as their workplace open but having lower patient volume than usual, while $26 \%$ had completely shut down and not seeing any patients. It can also be acknowledged that while $11 \%$ of the dentists indicated on having their workplace open and additional $62 \%$ seeing emergency cases only $42 \%$ were receiving the salary (figure 2).

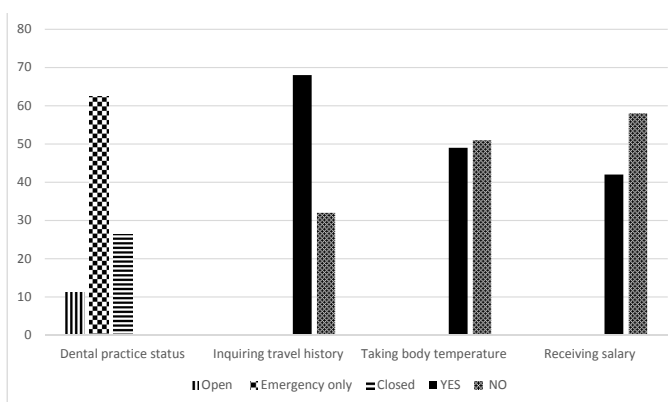

Figure 2. Dentist's work status, practice towards handling of patients and receiving salary status during the COVID-19.

The knowledge level of the dentists towards COVID-19 is presented in Table 1. Chi Square analysis to determine the association between knowledge attitude practice and impact on dentistry with baseline characteristics was done. The study reported no significant relationship between the dentist's responses with their year of practice and educational level in regarding knowledge about COVID-19 (Table 1). However, in case of preferred hand hygiene method for visibly soiled hands it was found statistically significant $(p=0.04)$ (Table 1).

Findings related to practice of the dentists towards inquiring about the travel history of the patients and taking their body temperature is shown in figure 2. A statistically significant difference regarding the impact and the practice during the COVID-19 was seen between GP and SP working at different workplace as shown in table 2. Impact of COVID-19 on dentists in the pandemic period is provided in figure 3 . It was found that $13.2 \%$ owned their own clinic and $77 \%$ were considering on letting go of their staffs because of the impact of COVID-19. Additionally, results of a poll done regarding what should be in top of mind of policy makersin the topics for dentist's support to combat the effects of COVID-19 in dental industry is shown in figure 4.

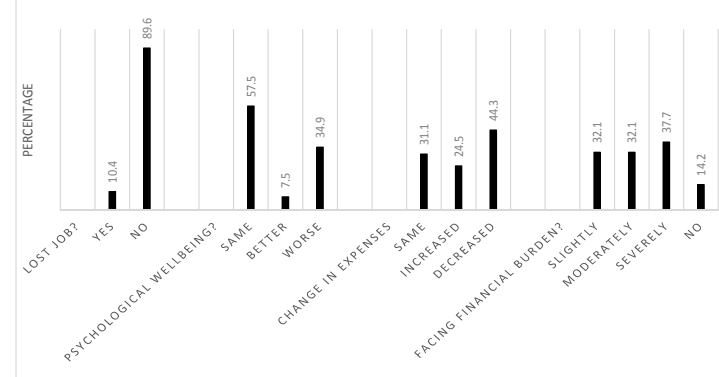

Figure 3. Impact of Covid-19 on dentists in the pandemic period.

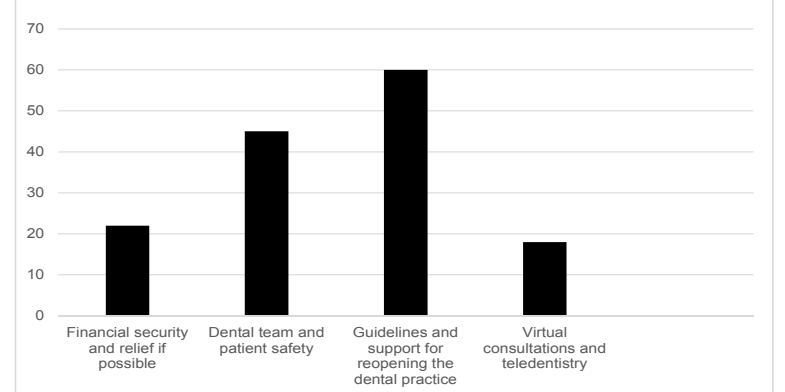

Figure 4. Participants views on what should be considered for dental support by the policy makers.

\section{DISCUSSION}

As the COVID-19 pandemic hits the world hard, third world countries like Nepal grapples to contain its menace with meager health facilities. As of this time, Nepal had a cascading effect in its number of cases with confirmed cases of 21,390 of COVID-19 disease with 60 deaths as of $5^{\text {th }}$ August 2020. Most of the dental treatments generate significant amounts of aerosols and droplets which can lead to rapid transmission of respiratory tract infections in the dental office. ${ }^{5}$ As, SARS-CoV-2 has been shown to survive in aerosols for hours and on some surfaces for days, the Occupational Safety and Health Administration (OSHA) has placed Dental health professionals in the very high exposure risk category. ${ }^{6,7}$ Additionally, the distance between the dentist and the working field is approx. $35-40 \mathrm{~cm}$, and certain dental treatments can require lengthy procedures, which puts the dentist at a higher risk of contracting COVID-19. ${ }^{8,9}$ Several reports have been emerging concerning the infection and deaths of health care professionals due to COIVD-19. In a recent clinical study, out of 138 hospitalized patients with SARS-CoV-2 
Table 1. The correct responses among different gender, age group and profession.

\begin{tabular}{|c|c|c|c|c|c|c|c|c|c|c|c|}
\hline \multirow[t]{2}{*}{ Correct Response } & \multicolumn{3}{|c|}{ Gender } & \multicolumn{5}{|c|}{ Years of experience } & \multicolumn{3}{|c|}{ GP/Specialist } \\
\hline & Male $\mathrm{n}(\%)$ & Female $\mathrm{n}(\%)$ & $P$ value & $<2 \mathrm{n}(\%)$ & $2-5 n(\%)$ & $5-10 n(\%)$ & $>10 \mathrm{n}(\%)$ & $P$ value & GP n(\%) & $\begin{array}{l}\text { Specialist } \\
\text { n (\%) }\end{array}$ & $P$ value \\
\hline Virus causing COVID-19 & $21(43.8)$ & $27(56.3)$ & .74 & 23(47.9) & $15(31.3)$ & $8(16.7)$ & $2(4.2)$ & .79 & $31(64.6)$ & $17(35.4)$ & .30 \\
\hline First reported case & $44(41.5 \%)$ & $62(58.5 \%)$ & & $53(50.0)$ & $32(30.2)$ & $15(14.2)$ & $6(5.7)$ & .09 & $74(70)$ & $32(30)$ & \\
\hline Modes of Transmission & $37(41.6 \%)$ & $52(58.4 \%)$ & .97 & $44(49.4)$ & $25(28.1)$ & $14(5.7)$ & $6(6.7)$ & .39 & $64(72)$ & $25(28)$ & .28 \\
\hline What is close contact & $23(42.6 \%)$ & $31(57.4 \%)$ & .37 & $24(44.4)$ & $19(35.2)$ & $8(14.8)$ & $3(5.6)$ & & $38(70)$ & $16(30)$ & .41 \\
\hline $\begin{array}{l}\text { Medical advice indica- } \\
\text { tion }\end{array}$ & $39(39.4)$ & $60(60.6)$ & .09 & $49(49.5)$ & $30(30.3)$ & $15(15.2)$ & $5(5.1)$ & .54 & $68(69)$ & $31(31)$ & .34 \\
\hline $\begin{array}{l}\text { Preferred method of } \\
\text { hand washing }\end{array}$ & $32(36.8)$ & $55(63.2)$ & $.04^{*}$ & $40(46)$ & $27(31)$ & $14(16)$ & $6(7)$ & .62 & $60(69)$ & $27(31)$ & .23 \\
\hline
\end{tabular}

*a $p<.05$ considered statistically significant between the groups.

Table 2. Difference of impact and practice during COVID-19 between general practitioner and Specialist and according to workplace.

\begin{tabular}{|c|c|c|c|c|c|c|c|c|}
\hline Questions & $\begin{array}{l}\text { General } \\
\text { Practitioner } \\
\text { n (\%) }\end{array}$ & $\begin{array}{l}\text { Specialist } \\
\mathrm{n}(\%)\end{array}$ & $\begin{array}{l}p \text {-value } \\
(p<0.05) \text { n (\%) }\end{array}$ & $\begin{array}{l}\text { Dental College } \\
\text { n (\%) }\end{array}$ & $\begin{array}{l}\text { Private Clinic } \\
\mathrm{n}(\%)\end{array}$ & $\begin{array}{l}\text { Private Hospital } \\
\text { n (\%) }\end{array}$ & $\begin{array}{l}\text { Government } \\
\text { Hospital } \\
\text { n (\%) }\end{array}$ & $\begin{array}{l}p \text {-value } \\
(p<0.05) \\
n(\%)\end{array}$ \\
\hline Have you lost job? & & & $0.21 *$ & & & & & 0.6 \\
\hline Yes & $11(15 \%)$ & 0 & & $1(2)$ & $8(20)$ & 0 & $2(12)$ & \\
\hline No & $63(85)$ & $32(100)$ & & $41(98)$ & $33(80)$ & $6(100)$ & $15(88)$ & \\
\hline Are you receiving salary? & & & $0.00^{*}$ & & & & & $0.00 *$ \\
\hline Yes & $18(24)$ & $26(81)$ & & $26(62)$ & $2(5)$ & 0 & 16(94) & \\
\hline No & $56(75)$ & $6(19)$ & & $16(38)$ & $39(95)$ & $6(100)$ & $1(6)$ & \\
\hline \multicolumn{3}{|c|}{ Are you taking body temperature? } & $0.001^{*}$ & & & & & $0.00 *$ \\
\hline Yes & $30(41)$ & $22(69)$ & & 29(69) & $13(32)$ & $2(33)$ & $8(47)$ & $0.00 *$ \\
\hline No & $44(59)$ & $10(31)$ & & $13(31)$ & $28(68)$ & $4(67)$ & $9(53)$ & \\
\hline \multicolumn{3}{|c|}{ Are you inquiring about travel history? } & $0.00 *$ & & & & & $0.00 *$ \\
\hline Yes & $41(55)$ & $31(97)$ & & $38(90)$ & $15(37)$ & $4(67)$ & 15(88) & \\
\hline No & $33(44)$ & $1(3)$ & & $4(10)$ & $26(63)$ & $2(33)$ & $2(12)$ & \\
\hline \multicolumn{3}{|c|}{$\begin{array}{l}\text { Are you keeping yourself updated with } \\
\text { COVID-19 news? }\end{array}$} & $0.008^{*}$ & & & & & 0.19 \\
\hline Yes & $74(100)$ & 29(91) & & 39(93) & $41(100)$ & $6(100)$ & $17(100)$ & \\
\hline No & 0 & $3(9)$ & & $03(7)$ & 0 & 0 & 0 & \\
\hline
\end{tabular}

*a $\mathrm{p}<.05$ considered statistically significant between the groups.

infected pneumonia in Wuhan, 29\% were health care workers. ${ }^{10}$ The increasing COVID-19 infections among the health care workers could be explained by their knowledge and practice towards SARS-COV 2 infections, the condition and strength of the health care system, the accessibility and availability of PPE, and continual study and its explanation. Therefore, this study aims to assess and investigate the awareness, preparedness, and knowledge of the dental professionals to combat the COVID-19 disease outbreak.

Most of the participants were found to be GP (69\%) with $<2$ years of work experience (50\%) which is similar to a study done by kamate et al. where $65 \%$ were GP with $34.5 \%$ having $2-5$ years of experience. ${ }^{11}$ In present study $45 \%$ of the participants were aware that the virus causing COVID-19 was initially termed as 2019-nCoV, later named as SARS-CoV-2. While the awareness level is low, it was greater than in the study conducted among healthcare workers in Mumbai where only $22.6 \%$ responded the same. ${ }^{12}$ The respiratory droplets are the main mode of transmission of the virus which was correctly reported by $84.1 \%$ of the participants. This finding too showed greater knowledge among Dentists than in the studies done in India and Pakistan where $62 \%$ and $79.2 \%$ of the health care workers correctly reported, respectively. ${ }^{12,13}$ This difference in awareness level must have been influenced by the fact that COVID-19 cases were in rise and the lockdown was starting to get flexible which concerned the dentists about their workplace safety. Similarly, $97 \%$ of the participants in present study considered themselves updated with knowledge and news on COVID-19 while Ahmed et al. reported only $67 \%$ of the healthcare workers doing the same, which might have been because of the difference in the education and professional level of the participants, which in their study included dental graduates as well as dental paramedics. ${ }^{13}$

It is recommended that patients presenting with 
continuous high fever along with persistent cough, sore throat, diarrheas, myalgia etc. should be registered as COVID-19 patients until proven otherwise and referred to the designated healthcare centers. ${ }^{2}$ It is also desired that all hospitals and clinics establish pre check triages of all patients enquiring upon their travel history, and measuring their body temperature once they are in the healthcare premises. In this study, $49 \%$ of the participants took body temperature of the patients which is similar to the study done in Kerala where $43 \%$ did the same. ${ }^{14}$ In this study, $68 \%$ of dentists were taking travel history which has become paramount during this pandemic. This finding agrees with that of the studies done by Kamate et al. and Indu et al. where $96.2 \%$ and $81 \%$ collected travel history from the patients, respectively. ${ }^{11,14}$ This can additionally play important part in a timely diagnosis, which may perhaps prevent further propagation of infection. In a lower middleincome country like Nepal, the expense of fumigation/ sterilization of the dental office, purchasing of extra PPE, masks, face shields, gloves etc. can severely affect the clinicians financially.

Physical/social distancing means an individual must keep distance or space between themselves and other people outside the house which is one of the most stressed precautionary measures to be employed by individuals to avoid contracting the disease. US CDC defined "close contact" as: "being within approximately 6 feet ( 2 meters) of a COVID-19 case for a prolonged period of time or having direct contact with infectious secretions of a COVID-19 case". ${ }^{15}$ Only $52 \%$ of the participants were able to define "close contact" correctly analogous to the study done in Mumbai where $48.9 \%$ of the total respondents answered accurately. ${ }^{12}$ This stresses on need of providing training and online courses among dentist such that each dentist is well adept to the information and updates regarding the COVID-19. We can also make use of various online webinars provided by the CDC and World Health Organizations (WHO) to access updated knowledge regarding the management and protocols in dental setting.

A majority of $95 \%$ of the participants were able to accurately answer question related to COVID-19 exposure that required medical attention which is in concurrence with the study conducted by Modi et al. where $87 \%$ of the responders answered the same. ${ }^{12}$ Health care professionals are always required to take standard precautionary measures in their routine practice considering each patient as infected or able to transmit infection. But the usual regular protective measures taken might not be effective due to the highly contagious nature and in some cases asymptomatic occurrence of SARS-COV-2 demanding extreme strict cross infection protocols. The corona viruses endure on inanimate surfaces like plastic, metal, glass for 9 days. ${ }^{16}$ In circumstances where hands are not visibly soiled and in non availability of soap and water, an alcohol-based hand sanitizer containing at least $60 \%$ of the alcohol can be used. ${ }^{17}$ However, the question in our study enquired on hand hygiene technique recommended for visibly soiled hands which is the use of soap and water for washing hands for at least 20 seconds with the whole process lasting or about $40-60$ seconds. The total of $82 \%$ responded with correct method greater than among healthcare workers in Mumbai where only $52 \%$ of the participants responded the same. $^{12}$

The study reported no significant relationship between the dentist's responses with their year of practice and educational level regarding knowledge about Covid-19 $(p<0.05)$ which was similar to the study by Modi et al. ${ }^{12}$ In a study conducted in Kerala, there was no significant association of KAP and age group and gender which is in concurrence with present study except in preferred method of hand hygiene for visibly soiled hands which was found statistically significant with gender $(p<0.05) .{ }^{14}$ Also, a statistically significant association regarding impact and practice during the COVID-19 was seen between GP and SP working at different workplace. Similar association between knowledge, practice and working status of participants were found statistically significant in study done in Kerala. ${ }^{14}$

In the study done by Kamate et al. KAP revealed that good knowledge scores were significantly associated with qualifications and the years of practice as opposed to this study where no statistical significance was found. ${ }^{11}$ The finding is in agreement with study done by Harapan et al. who reported that GP had a higher or better scores as compared to SP. ${ }^{18}$ This difference could be due to the global disparities in the structure of dental curriculum and involvement of undergraduates in any kind of research projects. On contrary various other studies and authors have documented findings of SP reporting better and significant knowledge scores as compared to the GP during the ZIKV and Ebola hemorrhagic fever pandemics. ${ }^{19-21}$ This possibly can be reasoned as postgraduate studies involves performing thesis and research works which demands them to be updated continually based on recent guidelines and evidence based practice.

Mental health issues among health care workers in COVID-19 situation has been documented. ${ }^{22,23}$ Numerous causes have been speculated for this altered mental health status including fear of contagion, social isolation, public perception of COVID-19 stigma, heightened necessity for infection control measures at dental operatory or at domestic settings, apprehensions for oneself/family's wellbeing, decreased accessibility to personal protection gears, along with core issues of financial insecurity and potential loss of income. ${ }^{24}$ In our study, 35\% reported of having their psychological wellbeing worsen during this pandemic. This is on par with a study done among Chinese population who reported $35 \%$ distress during COVID $-19 .{ }^{25}$ However, psychological distress was found higher among Indian endodontists and Iranian adults, reporting $52 \%$ and $61 \%$ respectively. ${ }^{26,27}$ Now, the difference could be multifold, primarily because the study done in India 
consisted of homogenous cohort of endodontists whereas our study consisted all dentist and dental specialist. Also, the Chinese and Iranian cohorts consisted of public and also had a significant number of populations infected with COVID-19, unlike Nepal. ${ }^{25,27}$ Similarly, study done among DHP in Kerala, $12.9 \%$ of people were highly stressed. $29.5 \%$, $27.3 \%$ of dentist and dental specialist were moderately and slightly stresses, respectively. ${ }^{14}$

Economic impact of COVID-19 pandemic is at a personal, community, national and global level, the burden of which can not be undervalued, as it presents potential influences on other spheres of life. ${ }^{28}$ Participants reporting financial burden was found to be $85 \%$ with $37 \%$ reported being severely affected. In present study, $10 \%$ of the participants reported of losing job and 58\% were not receiving salary. A study of Zhang et al. demonstrated that people who stopped working due to COVID-19 outbreak reported worse mental health and psychological wellbeing. ${ }^{29}$

The incidence of psychological disorder during this crisis can be reduced if the government provides financial security programs. ${ }^{30}$ In western countries such as France, Spain, UK having high level of COVID-19 infection, emergencies packages have been implemented that include loans, payouts to employees and companies to alleviate the economic impact. ${ }^{31}$ In present study $21 \%$ of the responders placed financial security and relief if possible, on top criteria for the dental support from policy makers. However, $60 \%$ responded for guidelines and support for reopening the dental practice from the policy makers. Other remaining focused on virtual consultation and tele dentistry.

The study is susceptible to limitations like selective invitation and selective response by close associates of the investigators which can skew the demographics and confound the responses. Similarly, to avoid the social desirability bias we avoided collecting any personal information and assured the participants regarding the confidentiality of their data. Also, due to the cross-sectional nature of the study and the employed sampling technique, the self-selection bias on the side of the respondents could have occurred. However, during the implementation of the pilot study itself, it was ensured that the questions were kept as neutral and simple as possible to avoid such bias.

\section{CONCLUSION}

The study shows that while majority of dental health professionals have good knowledge and awareness regarding the global pandemic, still there were certain pitfalls in attitude and practice level among the dental practitioners. For example, only $52 \%$ could accurately define close contact and only $49 \%$ were taking the body temperature. This calls out for need of more efficient training programs and recommendation of standard dental treatment protocols and precise guidelines to put into practice. Similarly, the article also provides a sneak preview of vulnerability of dental care providers psychological wellbeing, which can be useful for the formulation of a conceptual model that can be tested empirically in future research such as determining the association between the dental practitioners' mental health during and post COVID-19 outbreak. This study thus provides an insight in shaping future guidelines, stratagem, and policies to be implemented in dental settings such that appropriate information and training sessions could be given to dental practitioners to guarantee awareness and enthusiasm regarding this global emergency to deliver safe and quality patient care.

\section{REFERENCES}

1. Chen N, Zhou M, Dong $X$, et al. Epidemiological and clinical characteristics of 99 cases of 2019 novel coronavirus pneumonia in Wuhan, China: a descriptive study. Lancet. 2020;395(10223):507-513. doi:10.1016/S0140-6736(20)30211-7

2. Chang D, Xu H, Rebaza A, Sharma L, Dela Cruz CS. Protecting healthcare workers from subclinical coronavirus infection. Lancet Respir Med. 2020;8(3):e13. doi:10.1016/S2213-2600(20)30066-7

3. "Dental Hierarchy of Needs" in the COVID-19 Era - Or Why Treat When It Doesn't Hurt? - PubMed. https://pubmed.ncbi.nlm.nih. gov/32238979/. Accessed July 7, 2020.

4. Stein RA. Super-spreaders in infectious diseases. Int J Infect Dis. 2011;15(8):e510. doi:10.1016/j.ijid.2010.06.020

5. Harrel SK, Molinari J. Aerosols and splatter in dentistry: A brief review of the literature and infection control implications. J Am Dent Assoc. 2004;135(4):429-437. doi:10.14219/jada.archive.2004.0207

6. Guidance for Dental Settings. CDC. https://www.cdc.gov/ coronavirus/2019-ncov/hcp/dental-settings.html. Accessed July 7, 2020.

7. Osha. Guidance on Preparing Workplaces for COVID-19. https://www. osha.gov/Publications/OSHA3990.pdf , Accessed July 2020.

8. The Dentist's Operating Posture - Ergonomic Aspects - Pub Med. https://pubmed.ncbi.nlm.nih.gov/25184007/. Accessed July 7, 2020.

9. Meng L, Hua F, Bian Z. Coronavirus Disease 2019 (COVID-19): Emerging and Future Challenges for Dental and Oral Medicine. J Dent Res. 2020;99(5):481-487. doi:10.1177/0022034520914246

10. Wang D, Hu B, Hu C, et al. Clinical Characteristics of 138 Hospitalized Patients with 2019 Novel Coronavirus-Infected Pneumonia in Wuhan, China. JAMA - J Am Med Assoc. 2020;323(11):1061-1069. doi:10.1001/jama.2020.1585

11. Assessing Knowledge, Attitudes and Practices of dental practitioners regarding the COVID-19 pandemic: A multinational study.

12. Modi PD, Nair G, Uppe A, et al. COVID-19 Awareness Among Healthcare Students and Professionals in Mumbai Metropolitan Region: A Questionnaire-Based Survey. Cureus. 2020;12(4). doi:10.7759/cureus.7514

13. Ahmed N, Shakoor M, Vohra F, Abduljabbar T, Mariam Q, Abdul Rehman M. Knowledge, Awareness and Practice of Health care Professionals amid SARS-CoV-2, Corona Virus Disease Outbreak. Pakistan J Med Sci. 2020;36(COVID19-S4). doi:10.12669/pjms.36. covid19-s4.2704 
14. Syriac G, Beena VT, MCherian L, Paul S, Sathyan P, Professor A. Assessment of Knowledge, Attitude and Practice Regarding Dental Care during COVID 19 Pandemic-A Cross Sectional Study Among Dental Health Professionals In Tertiary Care Centers Of Kerala. IOSR J Dent Med Sci e-ISSN. 2020;19:5-10. doi:10.9790/0853-1905110510

15. Social Distancing, Quarantine, and Isolation. https://www.cdc.gov/ coronavirus/2019-ncov/prevent-getting-sick/social-distancing.html. Accessed July 7, 2020.

16. Kampf G, Todt D, Pfaender S, Steinmann E. Persistence of coronaviruses on inanimate surfaces and their inactivation with biocidal agents. J Hosp Infect. 2020;104(3):246-251. doi:10.1016/j.jhin.2020.01.022

17. Hand Hygiene: Why, How \& When? WHY? https://www.who.int/ gpsc/5may/Hand_Hygiene_Why_How_and_When_Brochure.pdf Accessed July 2020.

18. Harapan H, Aletta A, Anwar S, et al. Healthcare workers' knowledge towards Zika virus infection in Indonesia: A survey in Aceh. Asian Pac J Trop Med. 2017;10(2):189-194. doi:10.1016/j.apjtm.2017.01.018

19. Gupta N, Randhawa R, Thakar S, Bansal M, Gupta P, Arora V. Knowledge regarding Zika virus infection among dental practitioners of tricity area (Chandigarh, Panchkula and Mohali), India. Niger Postgrad Med J. 2016;23(1):33. doi:10.4103/1117-1936.180179

20. Gupta N, Mehta N, Gupta P, Arora V, Setia P. Knowledge regarding Ebola Hemorrhagic Fever among private dental practitioners in Tricity, India: A cross-sectional questionnaire study. Niger Med J. 2015;56(2):138. doi:10.4103/0300-1652.153405

21. Holakouie-Naieni K, Ahmadvand A, Raza O, et al. Assessing the knowledge, attitudes, and practices of students regarding ebola virus disease outbreak. Iran J Public Health. 2015;44(12):1670-6.

22. Greenberg N, Docherty M, Gnanapragasam S, Wessely S. Managing mental health challenges faced by healthcare workers during covid-19 pandemic. BMJ. 2020;368:m1211. doi:10.1136/bmj.m1211
23. Kang L, Li Y, Hu S, et al. The mental health of medical workers in Wuhan, China dealing with the 2019 novel coronavirus. The Lancet Psychiatry. 2020;7(3):e14. doi:10.1016/S2215-0366(20)30047-X

24. Caring for the Psychological Well- Being of Healthcare Professionals in the Covid-19 Pandemic Crisis - Pub Med. https://pubmed.ncbi.nlm. nih.gov/32268045/. Accessed July 7, 2020.

25. Qiu J, Shen B, Zhao M, Wang Z, Xie B, Xu Y. A nationwide survey of psychological distress among Chinese people in the COVID-19 epidemic: Implications and policy recommendations. Gen Psychiatry. 2020;33(2). doi:10.1136/gpsych-2020-100213

26. Nair AKR, Chellaswamy KS, Kattula D, Thavarajah R, Mohandoss AA. Perceived Stress and Psychological (Dis) Stress among Indian Endodontists During COVID19 Pandemic Lock Down.; 2020. doi:10.1101/2020.05.06.20092601

27. Afshar A, Phd J, Dinani MM, Madavani AN, Li J, Zhang SX. The distress of Iranian adults during the Covid-19 pandemic - More distressed than the Chinese and with different predictors. med Rxiv. April 2020:2020.04.03.20052571. doi:10.1101/2020.04.03.20052571

28. McKee M, Stuckler D. If the world fails to protect the economy, COVID-19 will damage health not just now but also in the future. Nat Med. 2020;26(5):640-642. doi:10.1038/s41591-020-0863-y

29. Zhang SX, C YW, Rauch A, Wei F. Unprecedented disruptions of lives and work - a survey of the health, distress and life satisfaction of working adults in China one month into the COVID-19 outbreak

30. Mihashi M, Otsubo Y, Yinjuan X, Nagatomi K, Hoshiko M, Ishitake T. Predictive Factors of Psychological Disorder Development During Recovery Following SARS Outbreak. Heal Psychol. 2009;28(1):91-100. doi:10.1037/a0013674

31. France, Spain and UK unleash rescue packages to help companies | Financial Times. https://www.ft.com/content/7eb398ac-6839-11ea800d-da70cff6e4d3. Accessed July 7, 2020. 